\title{
Movimento Higienista: construção da figura feminina
}

\author{
Hygienist Movement: construction of the female figure
}

\author{
Poliana Moreira Silva ${ }^{1}$ \\ Carla Denari Giuliani2
}

\begin{abstract}
RESUMO
compreender e analisar como as revistas femininas e os Manuais de Saúde foram influenciados pelo Movimento Higienista e como esse influenciou na formulação de regras, normas e condutas para as mulheres viverem e se comportarem em sociedade. MÉTODOS: estudo qualitativo, descritivo, documental e de caráter retrospectivo, realizado por meio da leitura das revistas "O Cruzeiro" e "Jornal das Moças" da década de 50 e de Manuais de Saúde dos anos 60. Os periódicos utilizados na pesquisa foram consultados via Web. Os volumes das revistas foram selecionados para pesquisa de forma aleatória, por meio de um sorteio simples, em que foram escolhidos cinco volumes de cada uma das revistas de acordo com cada ano da década de 50. Já os Manuais de Saúde, são documentos de domínio público que foram confeccionados na disciplina de Ciências por alunas que fizeram o curso Magistério. Posteriormente a leitura das fontes pesquisadas, analisou-se os textos e as imagens utilizando a análise de conteúdo.

RESULTADOS: as revistas femininas dos anos 50 eram fontes de informação importante para as mulheres. Revelavam transformações e permanências nos costumes, nas relações familiares, nas normas sociais e regras de comportamento e nos papéis atribuídos a homens e às mulheres. Os Manuais de Saúde apesar de terem sido confeccionados por alunas retratam praticamente os mesmos temas das revistas pesquisadas. Assim, notá-se a influencia do Movimento Higienista nas fontes pesquisadas. CONCLUSÃO: as revistas femininas e os Manuais de Saúde utilizados na pesquisa serviram como guias de comportamento social, familiar e religioso, reforçando o papel idealizado ou esperado da mulher na sociedade. O Movimento Higienista no Brasil contribuiu para formulação de regras, normas e condutas para as mulheres viverem e se comportarem em sociedade, assim como para a construção do modelo feminino por grande influencia das revistas femininas e dos Manuais de Saúde. PALAVRAS-CHAVE: Mulheres. Feminismo. Imprensa. Revistas Eletrônicas.
\end{abstract}

\footnotetext{
${ }^{1}$ Programa de pós-graduação em Ciências da Saúde. Faculdade de Medicina. Universidade Federal de Uberlândia (UFU), Uberlândia, MG, Brasil. E-mail: polianamoreira2004@gmal.com.

2 Doutora. Programa de Pós-graduação em História e Cultura pela Universidade Federal de Uberlândia, Brasil Email: denarigiuliani@bol.com.br
} 


\begin{abstract}
ABASTRACT
To understand and analyze how women's magazines and Health Manuals were influenced by the Hygienist Movement and how it influenced the formulation of rules, norms and behaviors for women to live and behave in society. METHODS: a qualitative, descriptive, documentary and retrospective study was performed through the reading of "O Cruzeiro" and "Jornal das Moças" magazines of the 1950s and of the Health Manuals of the 1960s. The journals used in the research were consulted via Web. The volumes of the journals were randomly selected through a simple lottery, in which five volumes of each of the journals were chosen according to each year of the 50s. The Health Manuals, however, are domain documents which were made in the school subject of Science by students who did the Magisterium course. After reading the sources searched, the texts and the images were analyzed using the content analysis. RESULTS: women's magazines from the 1950s were important sources of information for women. They revealed transformations and permanences in customs, family relations, social norms and rules of behavior, images and roles attributed to men and women. The Health Manuals, although they were made by students, show practically the same themes as the researched journals. Thus, we note the influence of the Hygienist Movement in the researched sources. CONCLUSION: Women's magazines and Health Manuals used in research served as guides to social, family and religious behavior, reinforcing the idealized or expected role of women in society. The Hygienist Movement in Brazil contributed to the formulation of rules, norms and behaviors for women to live and behave in society, as well as for the construction of the female model by great influence of women's magazines and Health Manuals.
\end{abstract}

KEYWORDS: Women. Feminism. Press. Electronic Magazines.

A escolha do tema desta pesquisa foi algo que emergiu de maneira natural, considerando que me surgiram inquietações sobre o papel secundário que as mulheres ocupavam na sociedade.

Durante muito tempo, a mulher foi representada na sociedade como um sexo frágil, submisso e com um único papel - a reprodução. Desde a Grécia antiga, grandes filósofos como Aristóteles, já sustentavam essa ideia de submissão da mulher e da superioridade do homem (MENDES RS, VAZ BJO, CARVALHO AF, 2015 p. 88-89).

O primeiro discurso a ser usado para a designação dos papéis sexuais e sociais é o grego. Platão, Hipócrates e Aristóteles, defendiam a superioridade masculina em detrimento da feminina em relação à saúde (as mulheres são fracas e doentes), à intelectualidade (os homens são mais inteligentes do que as mulheres), ao corpo (disposição dos órgãos sexuais), entre outros aspectos. Este é um discurso simbólico que desempenha a função de justificar a supremacia do homem (COLLING AM., 2015).

O discurso religioso que mostra o mito de criação com a expulsão de Adão e Eva do paraíso (simbologia retratada no Velho Testamento) ainda é utilizado para designar 
papéis e posições de gênero e criar representações femininas. Além disso, tem-se o discurso médico que faz uma descrição anatômica dos órgãos sexuais femininos e os representa como o inverso dos masculinos, atribuindo ao útero, o órgão que dá a identidade à mulher e que explica as características de uma fisiologia e de uma psicologia vulneráveis. Essa sujeição da mulher ao seu sexo transforma-se em submissão necessária ao homem.

Com isso, percebe-se que o papel atribuído às mulheres vem sendo construído desde a Grécia antiga.

Tem־se no Movimento Higienista ou Sanitarista, que surgiu no Brasil no fim do século XIX e início do XX, a reafirmação de conceitos relacionados ao papel atribuído às mulheres.

O Movimento surgiu como uma nova mentalidade, que se propunha a cuidar da população, educando e ensinando novos hábitos (GÓIS JUNIOR E., 2002, p. 47-52).

Neste contexto, a técnica de higienização foi instaurada. A medicina social ganhava espaço e através da política higiênica, as mulheres assumiram a função de educadoras dos filhos e cuidadoras da casa e dos maridos (COSTA JF, 2004).

A mulher foi então considerada como uma importante colaboradora na luta por uma sociedade melhor (MANSANERA AR, SILVA LC, 2000, p.115-137).

Dela era cobrada uma atuação "patriótica". Era alvo de campanhas que pediam sua colaboração contra os males que se alastravam pelo país. Através de artigos, de propaganda na imprensa e conferências, os higienistas pretendiam conscientizar a "mulher brasileira" para que ela se empenhasse na "profilaxia social".

As ideias higienistas foram aos poucos fazendo parte do íntimo das mulheres, assim, a elas foram impostas funções, atribuições e papéis dentro da sociedade.

O Movimento Sanitário juntamente com as políticas públicas, dão visibilidade ao mundo feminino, através da posição atribuída à mulher frente à maternidade e à família, colocando-a como principal atriz das mudanças sociais ocorridas nessa época (REIS AOA, ZIONI F., 1993, p. 472-477).

Assim, percebe-se que o Movimento Higienista, utilizou-se da figura feminina para o seu avanço, impondo às mulheres deveres e responsabilidades através das políticas higiênicas 
A pesquisa se justifica pelos seguintes aspectos: falta de estudos relacionados ao tema, ampliação dos horizontes para a compreensão do feminino dentro da sociedade, desconstrução de pré-conceitos, mitos e lendas sobre o papel da mulher na sociedade e entendimento das relações de gênero.

Percebe-se com este estudo que é possível não apenas compreender os significados que as mulheres têm de si mesmas, mas, como os conceitos são passados de geração em geração e quanto o Movimento Higienista reforça dentro dos Manuais de Saúde e das revistas femininas, o papel de submissão da mulher e de superioridade do homem.

Assim, o objetivo do presente estudo é compreender e analisar como as revistas femininas e os Manuais de Saúde foram influenciados pelo Movimento Higienista quando se refere à figura feminina e ao seu papel na sociedade. Ademais, busca-se refletir como este movimento influenciou na formulação de regras, normas e condutas para as mulheres viverem e se comportarem em sociedade.

\section{Métodos}

Para a construção deste trabalho foi realizado um estudo qualitativo, descritivo, documental e de caráter retrospectivo, por meio da leitura das revistas "O Cruzeiro" e “Jornal das Moças” da década de 50 e de Manuais de Saúde dos anos 60.

Os periódicos utilizados na pesquisa foram consultados via Web (Hemeroteca Digital Brasileira), por meio de arquivos digitalizados.

Os volumes das revistas foram selecionados para pesquisa de forma aleatória, por meio de um sorteio simples, em que foram escolhidos cinco volumes de cada uma das revistas de acordo com cada ano da década de 50. Totalizaram-se cem volumes lidos das duas revistas pesquisadas.

Foi efetuada a escolha dos periódicos “Jornal das Moças” e "O Cruzeiro”, pelo fato de serem voltadas ao público feminino, por serem de publicação nacional e de grande tiragem, além de estarem em seus auges na década de 50 como veículos de comunicação. 
Já os Manuais de Saúde, são documentos de domínio público que foram confeccionados nas disciplinas de Puericultura ou de Ciências, por alunas que fizeram o curso Magistério/Normal.

Posteriormente à leitura das fontes pesquisadas, analisaram-se os textos e as imagens, por meio da leitura de artigos científicos, livros e dissertações, comparando este aspecto com a realidade dos dias atuais.

Utilizou-se da análise de conteúdo que é um método muito usado na análise de dados qualitativos, compreendida como um conjunto de técnicas de pesquisa cujo objetivo é a busca do sentido ou dos sentidos de um documento (CAMPOS CJG, 2004,p. 611-614).

\section{Resultados e discussões}

\section{Revistas Femininas: "Jornal das Moças" e "o Cruzeiro"}

As revistas femininas dos anos de 1950 eram fontes de informação importante para as mulheres brasileiras, principalmente as de classe média urbana. Revelavamse em tais meios de comunicação, as transformações e permanências nos costumes, nas relações familiares, nas normas sociais e regras de comportamento e nos papéis atribuídos aos homens e às mulheres. Os periódicos eram capazes de formar gostos, opiniões, padrões de consumo e de conduta. Ademais, serviam de companheiras de lazer para suas leitoras fiéis, mas, também como guias de ação e conselheiras persuasivas (PINSKY CB, 2014).

Elas abordavam temas como moda, beleza, comportamento da mulher, maternidade, namoros, casamentos, receitas e dicas para ser uma "boa mãe" e uma "boa esposa", além de propagandas de eletrodomésticos, de móveis, de produtos de higiene e de beleza.

O “Jornal das Moças" circulou de 1914 até os anos 60, a publicação era semanal, no Rio de Janeiro, tendo tiragem nacional incluindo capitais e algumas cidades do interior de vários estados do país. Foi essencialmente dirigida ao público feminino, principalmente às moças das classes alta e média brasileira 
(ALMEIDA NMA, 2006).

Tal periódico ocupou o primeiro lugar na imprensa feminina em 1945 e o primeiro lugar entre as revistas femininas semanais durante a década de 508 .

As publicações eram divididas em seções, nas quais cada uma abordava temas ou assuntos específicos.

“O Jornal da Mulher", direcionado às boas esposas ou às recém-casadas que cuidavam do lar: traziam bordados, figurinos de moda e moldes de roupas para mulheres e crianças. Apresentavam modelos norte-americanos, franceses, italianos e brasileiros, em sua grande parte vestidos.

Figura 1. Vestidos femininos

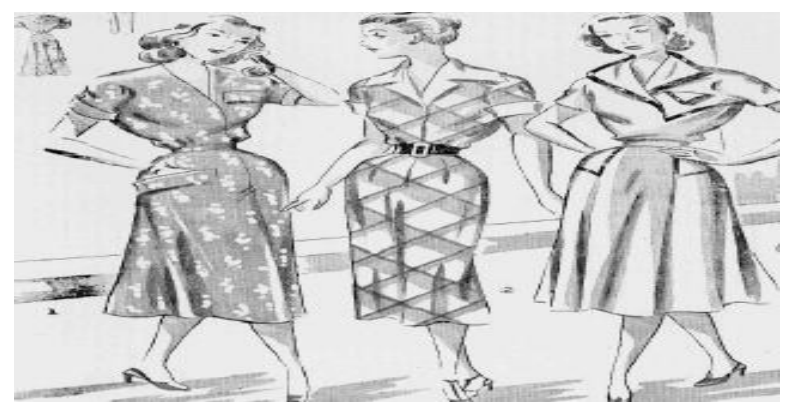

Fonte: Revista Jornal das Moças 27/12/1951 n 01906
Figura 2. Vestidos infantis

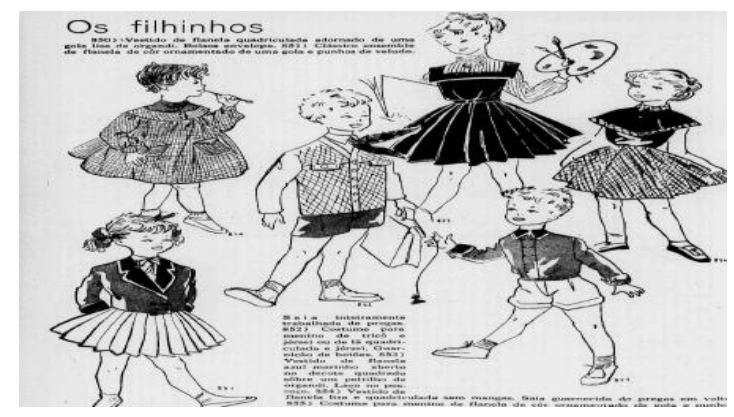

Fonte: Revista Jornal das

Moças 28/01/1954 n 02015

"O Evangelho das Mães" ("sagrada missão da maternidade") abordava principalmente o cuidado com os filhos.

A seção "Falando às mães" possuía conselhos médicos do Dr. Werther Leite Ribeiro que traziam dicas, informações e curiosidades.

Várias páginas da revista eram dedicadas à culinária, decoração da casa, organização do lar, dicas de beleza sobre maquiagem, cabelo e cuidados especiais com o corpo.

Havia também muitas propagandas de produtos para maquiagem, cremes para manchas na pele e para sardas, xampus e tintura para cabelos, sabonetes, perfumes, bolsas femininas, remédios, pomadas contra assaduras para bebês e cursos de corte e costura. 
Além disso, o periódico trazia contos, histórias e romances nos quais em geral se reforçavam "a moral e os bons costumes".

Outra seção da revista era "Troças e traços" que continham várias piadas sobre as mulheres. Em muitas delas as mulheres eram tidas como fúteis, super vaidosas, consumistas, pouco inteligentes, assim, retratadas de forma pejorativa, contrária à superioridade e à racionalidade masculina.

Nos exemplos a seguir, percebe-se que as piadas reforçam o preconceito sobre a incapacidade do raciocínio lógico, o hábito consumista e a futilidade das mulheres. Infelizmente, muitas das piadas presentes na revista "Jornal das Moças", ainda fazem parte do nosso cotidiano e continuam a ser engraçadas para muitos.

Figura 3. Piada - incapacidade de raciocínio das mulheres

Figura 4. Piada mulheres super vaidosas e consumistas

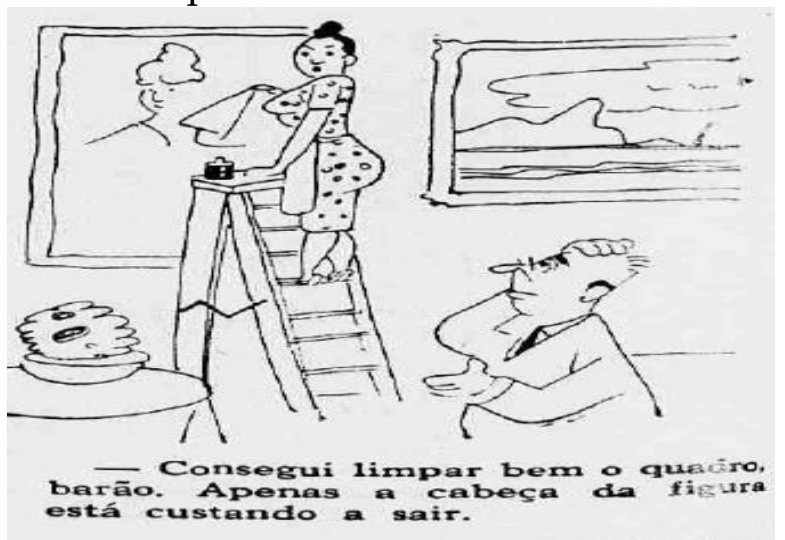

Fonte: Revista Jornal das Moças (1841) Jornal das Moças (1906) 27/12/1951

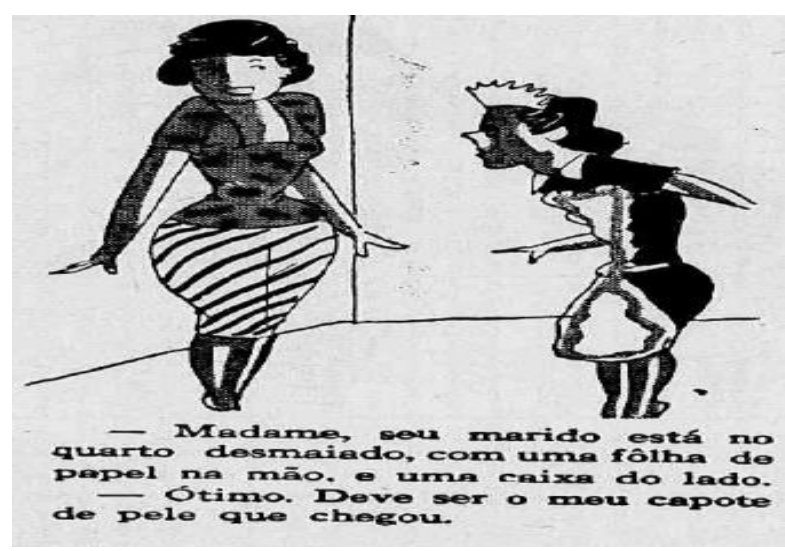

Fonte: Revista 
Além das seções mencionadas, são encontradas nas páginas das revistas conselhos dados às mulheres, como por exemplo: "não se deve irritar o homem com ciúmes e dúvidas" e "é fundamental manter sempre a aparência impecável diante do marido" (Jornal da Moças, 1957).

Já a revista "O Cruzeiro" foi fundada por Carlos Malheiro Dias, no Rio de Janeiro. De publicação semanal, circulou dos anos 1928 a 1975, tendo sua primeira edição publicada em novembro de 1928 pelos Diários Associados de Assis Chateaubriand.

Destacava-se como um dos meios de comunicação mais importantes da década de 50, presente nos lares de classe média urbana e lida por toda a família, de circulação nacional (MAGALHÃES AM, BOJUNGA CBRP, 2014 p.345-364).

Ao contrário da revista "Jornal das Moças", "O Cruzeiro" publicava temas como política, economia, cultura, arte, religião, história do Brasil, esporte, enfim, trazia questões de interesse geral. Além disso, também haviam textos e matérias destinadas às mulheres.

Suas páginas, normalmente, eram divididas nos seguintes títulos: artigos, reportagens, seções, humorismo, conto e romances, cinema, figurinos e assuntos femininos ou para a mulher. Este último título era subdividido em: "Da Mulher para a Mulher", "Elegância e Beleza" e "Lar, Doce Lar".

"Da Mulher para a Mulher" trazia conselhos e respostas às cartas de leitoras e leitores dados por Maria Teresa, no qual grande parte dos assuntos abordados eram casamentos, namoros, traições e "assuntos do coração".

Já a seção "Elegância e Beleza", dedicava suas páginas à moda, dicas e conselhos de beleza, figurinos e chapéus femininos, dietas, entre outros temas.

"Lar, Doce Lar" continha várias receitas, reportagens de decoração e organização da casa, artigos sobre como fazer festinhas de crianças, dentre outros assuntos. 
Além disso, várias páginas do periódico eram dedicadas às propagandas de eletrodomésticos, produtos de higiene e perfumaria, maquiagem, roupas femininas e medicações para crianças.

Por fim, dentro do título Humorismo, havia também o subtítulo "As Garotas Alceu Penna e A. Ladino" representadas por ilustrações de mulheres jovens que davam dicas de moda e sobre assuntos como paqueras, cozinha e passeios. O humor presente nessa seção frequentemente era voltado para piadas que desvalorizavam e ridicularizavam as mulheres.

De acordo com o exposto, percebe-se que as revistas, "Jornal das Moças" e "O Cruzeiro", publicam e tratam os temas relacionados às mulheres de forma semelhante. Abordam praticamente do mesmo modo, os mesmos assuntos, de modo geral são eles: consumismo, maternidade, casamento, organização do lar, moda, beleza, conselhos e piadas.

A representação feminina na década de 50 se baseava sobre a ideia de mulher como "rainha do lar". Assim, a ideologia da mulher como essencialmente afeita ao lar, ao casamento e à maternidade era amplamente difundida nas revistas, em contraposição às representações masculinas, uma vez que os homens eram considerados como "chefes de família", provedores, cabendo a eles o trabalho fora de casa e o sustento familiar (HEINE P., 2015, p.62-67).

Logo, nessa década, era forte a perspectiva de que as mulheres deveriam estar "preparadas" para a administração de um "novo lar". Isso se dava, tanto no nível de uma educação escolar, quanto em uma educação informalmente disseminada pelas tradições orais e, também, a partir da imprensa feminina, aqui em especial, revistas. Nessa época, o mundo de grande parte do feminino estava repleto de orientações que abrangiam os trabalhos de agulha, bordado, costura e música, bem como, conhecimentos de temas relacionados à cozinha, manutenção da roupa, cuidados com a limpeza da casa e higiene (PILLA MCBA, 2015, p. 623-635).

Essa representação feminina tem origem no Movimento Higienista ou Sanitarista, no qual a mulher foi considerada peça chave para o desenvolvimento das ideias higienistas. 
Dessa maneira, compreende-se que os textos e as imagens dispostos nas revistas femininas pesquisadas são frutos do Movimento Higienista, trazendo em suas páginas normas e regras de comportamento às mulheres, gerando preconceitos contra elas, definindo os papéis e atribuições dos homens e das mulheres na sociedade, reforçando as relações familiares tendo a figura feminina como "rainha do lar", conforme previamente dito, e as mudanças e permanências nos costumes.

$\mathrm{O}$ feminino nas revistas aparece reduzido à sua expressão mais simples e simplória: consumidoras, fazendo funcionar poderosos setores industriais ligados às suas características "naturais": domesticidade (eletrodomésticos, produtos de limpeza, móveis), sedução (moda, cosméticos, o mercado do sexo, do romance, do amor) e reprodução (produtos para maternidade / crianças, da vestimenta / alimentação aos brinquedos) (KOBAYASI E, HOCHMAN G, 2015, p.67-89).

As revistas incentivavam o consumo, pois várias propagandas (imagens e textos) falavam sobre moda, sobre compra de eletrodomésticos para o lar, conselhos de beleza, produtos para bebês, tudo que estivesse ligado à compra de algum produto.

Os anúncios representaram a celebração de novos hábitos de higiene e de consumo que deveriam ser buscados pela sociedade brasileira, um processo no qual a publicidade desempenhou um papel central de difusão e oferta desta nova maneira, moderna e saudável de se viver ${ }^{14}$.

No contexto de higienização, a família passou a ter um novo significado.

Um novo modelo materno foi construído para as mulheres burguesas e aceito por elas, que atendiam aos conselhos médicos sem hesitar, tornando-se mães devotadas, que se sacrificam pelos filhos, passando a amá-los de uma maneira intensa, o que é designado por muitos como instinto materno (LEMOS FCS, VASCO DS, 2012, p.1-20).

Nas seções "O Evangelho das Mães" e "Falando às mães" do "Jornal das Moças", percebe-se que a revista trata a maternidade como uma função social da mulher. Como se a maternidade fosse algo inato, inerente a todas as mulheres, quase uma obrigação social.

Dentre todas as funções sociais exercidas pela mulher, a maternidade é pontuadamente a que adquiriu maior valor social (GRANT WH, 2002). 
Em relação ao casamento, esses periódicos mostram claramente as atribuições dos maridos e das esposas. O homem é visto como "chefe da casa" e deve sustentá-la economicamente, enquanto que a mulher deve se ocupar com os afazeres domésticos e com os cuidados com os familiares.

É como se a felicidade conjugal dependesse das atividades e cuidados da mulher dentro do lar. Uma esposa que não cuidasse bem do lar, do marido e dos filhos, possivelmente, não teria um casamento feliz. Além disso, ela deveria se preocupar com a beleza.

A valorização da beleza feminina é um dos temas abordados nos periódicos. As revistas ensinavam que a boa aparência da esposa é um atributo essencial para a felicidade conjugal, pois mantém a atenção do marido e evita o risco de perdê-lo.

Em algumas páginas, estavam presentes conselhos destinados às mulheres. Os conselhos dados pelas revistas eram marcados por valores morais que favoreciam as experiências sexuais masculinas, enquanto procuravam restringir e controlar a sexualidade feminina, classificando os comportamentos em certos e errados, aceitáveis e inadmissíveis e as garotas em "moças de família" e "levianas" (ou "de programa"). Às "moças de família", a moral dominante garantia o respeito social e as possibilidades de um casamento nos moldes tradicionais que as "elevava" à condição de "rainha do lar"(BARSSANEZI C, USINI LB, 1995, 243-260).

Ao se tratar de saúde e nutrição da família são as mulheres que costumam ser as responsáveis pelo bem-estar dos demais membros do grupo. Os registros culinários brasileiros ao longo dos séculos XIX e XX foram dirigidos e/ou elaborados quase que exclusivamente por mulheres

Em relação às piadas, o humor presente nas revistas da época passava mensagens de que as mulheres eram fúteis, escravas da moda, extrema e ridiculamente vaidosas (especialmente com relação à idade). Além disso, mostravam que as mulheres tinham como características a competitividade e as agressões verbais mútuas, devido à inveja ou disputa pelas atenções masculinas, que eram fofoqueiras ou falavam demais, que as solteiras buscavam desesperadamente o casamento, dentre outros assuntos. 
Nota-se que, infelizmente, muitas das piadas mencionadas nestas revistas, ainda estão presentes nos dias atuais sendo propagadas e tidas como engraçadas.

Enfim, os textos e as imagens abordados nas revistas "Jornal das Moças" e "O Cruzeiro" são retrato do Movimento Higienista, pois seus conteúdos se enquadram na normalização e padronização da sociedade trazida pelo movimento. Assim, apesar de todas as mudanças e transformações ocorridas na sociedade brasileira, em especial, ao que se refere às mulheres, até os dias atuais como hábitos, costumes, regras, normas de comportamento, ainda fazem parte do nosso cotidiano.

\section{Manuais de saúde}

Os Manuais de Saúde eram confeccionados nas disciplinas de Puericultura ou Ciências do curso Magistério ou Normal. As mulheres, quando faziam o curso, o famoso "espera marido", aprendiam as disciplinas próprias para serem professoras do chamado ensino primário. Além disso, faziam disciplinas que futuramente as ajudariam no domínio da casa, das crianças e do marido. Assim, o canto, a costura, o bordado, a puericultura, os trabalhos manuais e outras atividades, eram matérias fundamentais para aquelas que seriam boas esposas, mães e donas de casa. Por que não dizer que se transformariam em "rainhas do lar"?

A educação feminina formal, por exemplo, por meio do ensino público, passou a ser apontada como um meio de criar condições para regenerar a sociedade. Mesmo que sua visão em relação à mulher fosse ainda muito conservadora, suas funções sociais como mãe e esposa passaram a ser mais valorizadas. Inclusive, os médicos higienistas possuíam um discurso que reconheciam a importância da família e sua influência na construção da sociedade. Por isso mesmo, era preciso instruí-las de forma a terem condições de desempenharem bem as funções que a sociedade esperava delas.

De acordo com esses Manuais, os tópicos frequentemente abordados se referem ao namoro, noivado, casamento, gestação/maternidade e educação dos filhos.

A responsabilidade pela criação da nova família formada por pai, mãe e filhos, coube à Higiene, entendida como parte da ciência médica que dá os preceitos e as regras necessárias, tanto à aquisição como à conservação da saúde e se referem a 
exercícios, banhos, sonos, enfim, ensina a evitar coisas nocivas e a fazer bom uso das coisas úteis (COSTA JF, 1979).

Percebe-se que os Manuais de Saúde apesar de terem sido confeccionados por alunas, retratam praticamente os mesmos temas das revistas pesquisadas, com ênfase nos relacionamentos afetivos (namoro, noivado e casamento) e na maternidade. Assim, neles também notam-se a influência do Movimento Higienista, em especial, ao que se refere à formação da família e à amamentação.

Figura 5. Técnica da Amamentação

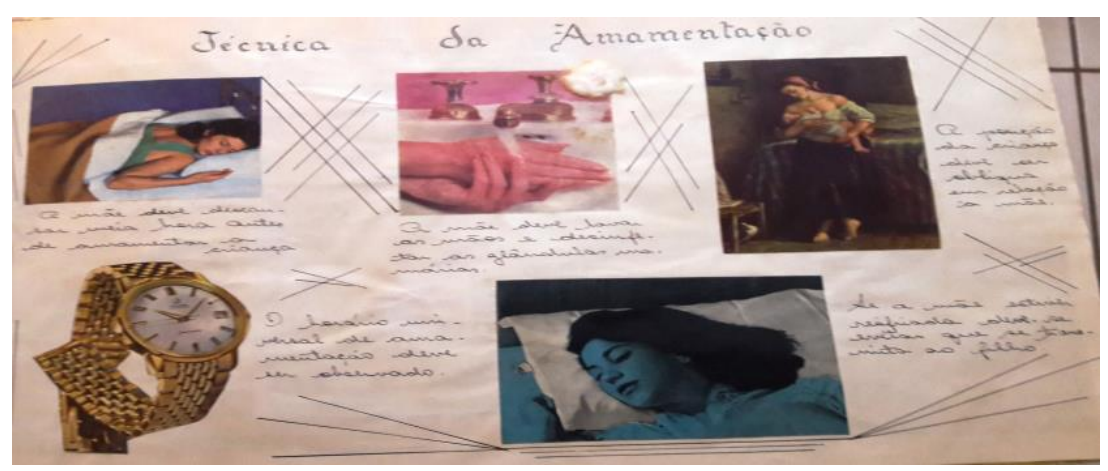

Fonte: Manual de Saúde (1960)

O Movimento Higienista designa o pensamento dos médicos e especialistas do século XIX que teve a maternidade e o aleitamento como principais focos de atuação. Até o século XVIII, as mulheres se negavam a amamentar os seus filhos por variados motivos: era um ato despudorado, perderiam a beleza, não era digno, remetia a uma imagem animalizada, entre outros motivos (TOURINHO JG, 2006, p.1-33).

Já sob a influência do Movimento Higienista, a amamentação se transformou em prova de amor materno, tornou-se parte de um padrão de comportamento valorizado, mas também uma forma de regulação da vida da mulher através da mobilização do sentimento culpa. Pelo Movimento Sanitarista chegou-se a comparar as mulheres que não amamentavam as feras, o amor materno se distanciou um pouco, mas não muito do caráter biológico e passou a se configurar como um dever moral para com a sociedade 19 .

Isso é visto até hoje, pois várias campanhas são realizadas com o intuito da valorização do aleitamento materno como algo que reflete o amor da mãe pelo filho. 
Além disso, encontram-se nos Manuais, imagens e textos que se referem aos papéis atribuídos às mulheres na sociedade: preocupação com a saúde, asseio e cuidados com o corpo, em especial na gestação, como se comportar durante o namoro e o noivado, atributos femininos (atribuições das "boas moças"), dentre outros aspectos.

Os ideais de "boa moça" propagados na sociedade, ensinados nas escolas, reproduzidos nas famílias, presentes nas expectativas sociais - eram de "moças de família". Sonhavam com o casamento, preservavam as aparências, eram donzelas e cristãs, respeitavam os mais velhos, mas valorizavam muito a juventude (especialmente a aparência física e as possibilidades de diversão nessa fase da vida)17.

Assim como as revistas pesquisadas, os Manuais de Saúde, também tiveram raízes no Movimento Higienista e se tornaram guias a serem seguidos por muitas mulheres que cursaram o magistério.

\section{Considerações finais}

Apesar de todas as transformações históricas ocorridas no século XX, o preparo da comida, a manutenção e organização da casa, as tarefas domésticas, o cuidado e a educação dos filhos, ainda é um papel considerado "naturalmente" feminino em muitos dos lares brasileiros.

Evidencia-se nos dias atuais, a conservação de conceitos e aspectos referentes às mulheres como, por exemplo: o papel feminino no lar (cuidadora da casa, dos filhos, do marido), a valorização da beleza, a infidelidade masculina como característica do homem, piadas que retratam de forma pejorativa as mulheres e até hoje são consideradas engraçadas, a superioridade masculina em relação à inteligência, dentre outros exemplos.

Enfim, são vários fatos que ainda permanecem no íntimo das pessoas que acabam por gerar preconceitos contra as mulheres.

A representação da mulher nas fontes pesquisadas contribuiu para reproduzir estereótipos associados à imagem feminina, deixando claro que, apesar das várias conquistas femininas nas últimas décadas, a consolidação efetiva da imagem de uma nova mulher ainda não foi plenamente alcançada. 
Assim, percebe-se que as revistas femininas e os Manuais de Saúde utilizados na pesquisa, serviram como guias de comportamento social, familiar e religioso, reforçando o papel idealizado ou esperado da mulher na sociedade.

Portanto, entende-se que o Movimento Higienista no Brasil contribuiu para a construção do modelo feminino no decorrer da década de 50 e 60 por grande influência das revistas femininas e dos Manuais de Saúde. Ele contribuiu para formulação de regras, normas e condutas para as mulheres viverem e se comportarem em sociedade.

\section{Referências}

ALMEIDA, NMA.Revistas femininas e educação da mulher: o Jornal das Moças. Fortaleza: Universidade Estadual do Ceará, 2006. Disponível em: http://alb.com.br/arquivomorto/edicoes_anteriores/anais16/sem03pdf/sm03ss14_06.pdf. Acesso em: 4 jun. 2017.

BARSSANEZI C, Ursini LB. O cruzeiro e as garotas. Cadernos Pagu. 1995; (4): 243260.

CAMPOS CJG. Método de análise de conteúdo: ferramenta para a análise de dados qualitativos no campo da saúde. Rev Bras Enferm. 2004; 57(5):611-614. 8Pinsky CB. Mulheres dos Anos Dourados. 1. ed. São Paulo: Contexto, 2014. 396 p.

COLLING AM. A construção histórica do corpo feminino. Cad Espaço Feminino. 2015;28(2):1981-3082.

COSTA JF. Ordem médica e norma familiar. 5.ed. Rio de Janeiro: Graal, 2004. 282 p.

GÓIS JUNIOR E. "Movimento Higienista" na história da vida privada no Brasil: do homogêneo ao heterogêneo. Rev. Cient. 2002;1(1):47-52.

GRANT WH. A Maternidade, o Trabalho e a Mulher. In: COLÓQUIO DO LEPSI IP/FE-USP. 2002. Disponível em:

$<$ http://www.proceedings.scielo.br/scielo.php?script=sci_arttext\&pid=MSC0000000032 001000300008\&lng=en\&nrm=abn>. Acesso em: 12 jun.2017.

HEINE P. Corpo e discursivização da mulher na revista jornal das moças da década de 50. Rev Eletr de Est do Discurso e do Corpo. 2015; 8(2):62-67.

LEMOS FCS, Vasco DS. Alguns percursos históricos entre o higienismo e a medicalização na atenção à infância e às famílias. Rev do Difere. 2012; 2(4):1-20. 
MAGALHÃES AM, Bojunga CBRP. Segredos da história do Brasil revelados por Gustavo Barroso na revista O Cruzeiro (1948-1960). Rev Est Históricos. 2014; 27(54):345-364.

MANSANERA AR, Silva LC. A influência das ideias higienistas no desenvolvimento da psicologia no Brasil. Psicol. Estud. 2000; 5(1):115-137.

MENDES RS, Vaz BJO, Carvalho AF. O movimento feminista e a luta pelo empoderamento da mulher. Rev Gênero e Direito. 2015;4(3): 88-99.

PILLA MCBA. Fontes para história da alimentação e patrimônio alimentar: a coluna "Vamos preparar os quitutes", no Jornal das Moças, nos anos 1950. Demetra: alimentação, nutrição \& saúde. 2015;10(3):623-635.

REIS AOA, Zioni F. O lugar do feminino na construção do conceito de adolescência. Rev de Saúde Pública. 1993; 27(6):472-477.

SWAIN TN. Feminismo e representações sociais: a invenção das mulheres nas revistas "femininas". História:Questões \& Debates. 2001;(34):11-44.

TOURINHO JG. A mãe perfeita: idealização e realidade - algumas reflexões sobre a maternidade. IGT na Rede. 2006; 3(5):1-33.

KOBAYASI E, Hochman G. $O$ " $C C$ " e a patologização do natural: higiene, publicidade e modernização no Brasil do pós-Segunda Guerra Mundial. In: Anais do Museu Paulista, São Paulo, 2015; v. 23. n.1. p. 67-89.

Recebido em outubro de 2018. Aprovado em novembro de 2018. 